\title{
Microbiota, regulatory T cell subsets, and allergic disorders
}

CASPar OHNMAcht

Institute for Allergy Research, Center of Allergy \& Environment (ZAUM), Technische Universität München \& Helmholtz Zentrum München, Neuherberg, Germany

\section{Key words \\ Microbiota - regulatory $\mathrm{T}$ cells \\ - tolerance \\ mechanisms - \\ type 2 immune \\ response}

\section{Submitted}

December 27, 2015

\section{Accepted}

January 26, 2016

\section{Abstract}

Epidemiologic studies revealed a crucial role of the environment for the increased prevalence of allergic disorders. The microbiota as part of our immediate environment promotes immune diversity that facilitates a well-equilibrated balance between immunity and tolerance. Alterations of our symbiotic microbiota especially in early life is thought to play a fundamental role in defining susceptibility to the development of allergic diseases during adult life on the population level. Due to a high density of bacteria, viruses and fungi and a large contact surface area for host-microbiota interactions, the most relevant interaction between microbes and our immune system are thought to occur in the gut. The immune system co-evolved with the symbiotic microbiota and adopted a variety of mechanisms to allow a dynamic state of tol-

\section{Introduction}

The differentiation of naive T cells to interleukin-4(IL-4)-secreting T cells is one of the hallmarks of allergy. For a long time, it was completely unclear why and how harmless antigens/allergens provoke in certain individuals the differentiation of $\mathrm{T}$ helper (Th) 2 cells. In contrast, it is well known that exposure of naive T cells to the cytokine IL- 4 is a key event for triggering Th2 differentiation which will become self-sustaining as soon as the differentiating Th 2 cells start to produce this cytokine themselves [1]. The cellular source of the initial IL-4 has remained enigmatic because neither naive $\mathrm{CD} 4{ }^{+} \mathrm{T}$ cells nor dendritic cells are able to produce IL-4 themselves. However, a variety of innate or "innate-like" cells that carry the transcriptional capacity to rapidly secrete IL-4 without prior differentiation steps were identified in newly generated reporter mice; these include basophils, eosinophils, mast cells, $\gamma \delta$ T cells, and natural killer T (NKT) cells [2]. Additionally, a newly identified cell type called innate lymphoid cell type 2 (ILC2) is thought erance, including the induction of regulatory T cells (Tregs). Foxp3-expressing Tregs are welldescribed immune regulators in autoimmune and allergic disorders. However, recent years have shown that Tregs can come in different flavours with different regulatory potential and outcome for our immune system. This review summarizes novel findings from basic immunology research that may help to better understand the interaction between the microbiota, differentiation of Tregs and its consequences for the onset and regulation of allergic disorders.

Cite this as Ohnmacht C. Microbiota, regulatory T cell subsets, and allergic disorders. Allergo J Int 2016;25:114-23

DOI: $10.1007 / \mathrm{s} 40629-016-0118-0$

to be critical for the induction and amplification of type 2 immune responses [3].

More than 25 years ago, Mosmann and colleagues discovered that Th2 differentiation is counter regulated through the cytokine interferon- $\gamma($ IFN- $\gamma)$ [4]. This resulted in the Th1/Th2 concept of T helper cell differentiation: IL- 4 counteracts the effect of IFN- $\gamma$ and thus the differentiation of Th1 cells whereas IFN- $\gamma$ blocks the differentiation of Th 2 cells. The basis of this discovery is still used today for the treatment of patients that suffer from Th2-dominated allergic diseases: the repeated exposure to defined amounts of allergens is used to induce a Th1-dominated immune response that helps the immune system to overcome a pro-allergic Th2 immune response. A second possibility of the immune system for regulation of Th2-dominated immune responses lies in the generation of allergen-specific regulatory T cells (Tregs).

However, it is not clear which extrinsic factors determine whether allergen-specific Th 2 cells or allergen-specific Tregs are induced or whether certain 
Treg subsets are generated to suppress pro-allergic immune responses. The decision of the immune system between Th2 and Treg induction upon recognition of harmless antigens may indeed reflect the immunological difference between allergic and non-allergic individuals and a better understanding of this decision is therefore of high relevance. In recent years, it has also become clear that the induction of Tregs is influenced by symbiotic microbes and may therefore provide one possible link between our environment and the susceptibility to allergic disorders.

\section{Link between Tregs and microbiota}

More than 25 years ago, Strachan was the first to propose the so-called "hygiene hypothesis" [5]. He observed an increased frequency of atopic diseases such as hay fever in households of wealthier families. Strachan attributed this phenomenon to reduced infection rates during early childhood due to declining family sizes, improvements in household amenities, and higher standards of personal hygiene

\begin{tabular}{|c|c|}
\hline \multicolumn{2}{|c|}{ Abbreviations } \\
\hline CNS3 & Conserved noncoding sequence 3 \\
\hline CTLA-4 & Cytotoxic T lymphocyte antigen 4 \\
\hline DSS & Dextran sulfate sodium \\
\hline $\mathrm{EAE}$ & $\begin{array}{l}\text { Experimental autoimmune } \\
\text { encephalomyelitis }\end{array}$ \\
\hline Foxp3 & Forkhead box protein \\
\hline HDM & House dust mite \\
\hline IL & Interleukin \\
\hline IPEX & $\begin{array}{l}\text { Immunodysregulation polyendo- } \\
\text { crinopathy X-linked syndrome }\end{array}$ \\
\hline ILC2 & Innate lymphoid cell type 2 \\
\hline ILC3 & Innate lymphoid cells type 3 \\
\hline IFN- $\gamma$ & Interferon- $\gamma$ \\
\hline IRF4 & Interferon regulatory factor 4 \\
\hline LPS & Lipopolysaccharide \\
\hline NKT & Natural killer T cell \\
\hline PSA & Polysaccharide A \\
\hline $\mathrm{ROR}(\gamma \mathrm{t})$ & $\begin{array}{l}\text { Retinoic acid-related orphan } \\
\text { receptor gamma t }\end{array}$ \\
\hline SCFA & Short-chain fatty acids \\
\hline SFB & Segmented Filamentous Bacteria \\
\hline TCR & T cell receptor \\
\hline Th & Thelper cell \\
\hline tTregs & Thymic Tregs \\
\hline TSDR & Treg-specific demethylated region \\
\hline
\end{tabular}

[5]. These attributes may be seen as part of a more broad change in lifestyle during the last century that includes reduced exposure to livestock and helminth infections, higher rates of caesarean sections, and increased use of antibiotics. All of these factors have been proposed to contribute to the allergy epidemic particularly observed in "westernized" countries. Fundamental support of the hygiene hypothesis comes from epidemiological data comparing rural to urban areas as well as children grown up with farm animal exposure vs. no such exposure. From such studies it has become clear that growing up in rural areas protects from allergic disorders possibly by a relative increase in bacterial or fungal diversity $[6,7]$. Nonetheless, the immunologic mechanism remains to be established.

Very recently, it was shown that low-dose exposure to lipopolysaccharide (LPS), a cell-wall component of gram-negative bacteria, has protective effects in a mouse model of house dust mite allergic lung inflammation [8]. This protective effect required expression of a factor called A20 (encoded by Tnfaip3) by epithelial cells. Importantly, asthmatic patients showed reduced levels of A20 in epithelial cells which might render these patients more susceptible to allergic asthma due to failed LPS tolerance induction [8]. The proposed mechanism can be mimicked in murine models and might explain how early life exposure to farm dust can protect from the development of allergic disorders later in life.

Remarkably, nearly all of the lifestyle factors that have been included in the hygiene hypothesis can be expected to directly or indirectly influence the composition of our microbiota. Especially the intestinal microbiota is known to heavily impact on the local and systemic immune system due to a long co-evolution of the host with symbiotic bacteria, the presence of numerous immune cells, and a large intestinal contact area to the microbial world. The most relevant observations for immune tolerance are derived from mice raised under germfree conditions because such mice show drastically reduced frequencies of Tregs in the gut $[9,10]$ but not in the skin [11]. Additional murine studies identified individual bacterial strains that have a very strong impact on the immune system. For instance, a product of Bacteroides fragilis called Polysaccharide A (PSA) has been shown to be sufficient for the maturation of the adaptive immune system and correcting the Th1/Th2 balance in germfree mice [12], most likely by promoting the induction of Tregs and IL-10 secreting T cells [13]. Furthermore, a consortium of clostridia species has been shown to enhance the induction of Tregs in the intestinal lamina propria [9].

Mechanistically, the fermentation of complex carbohydrate fibres by the microbiota leads to the pro- 
duction of short-chain fatty acids (SCFA) that have been shown to boost the generation of Tregs $[14,15]$. SCFA and most notably butyrate alter the acetylation pattern at certain histone residues of the Foxp3 promoter or so-called conserved noncoding sequence 3 (CNS3) next to promoter of the forkhead box protein 3 (Foxp3) [14, 15] and may thus serve as an epigenetic rheostat for Treg function and thus tolerance [16]. Besides their direct effect on the immune system, SCFA can also serve as a fuel for colonocytes and thereby enforce the epithelial barrier to prevent overt immune activation due to a too close contact of the immune system and the symbiotic microbiota [17]. A complex microbiota leads directly to mutualistic Treg induction when re-introduced into germfree mice [10].

Besides the promotion of Tregs, the microbiota also induces primarily pro-inflammatory $\mathrm{T}$ helper cell subsets such as Th1 or Th17 cells. A certain member of the microbiota, the so-called Segmented Filamentous Bacteria (SFB), by default provokes a drastic increase of Th17 cells in the lamina propria of the ileum [18]. Similarly, colonization of the skin with Staphylococcus epidermidis results in restoration of normal numbers of dermal Th17 cells compared to germfree mice [11]. The physiologic role of a dominantly type-17 response in the intestine supposedly lies in the induction of innate mechanisms protecting the epithelium from bacterial or fungal invasion as well as to allow rapid expulsion of those pathogens that do breach the epithelial barrier [19, 20].

Th17 cells, however, also play a prominent role in many autoimmune and autoinflammatory diseases such as experimental autoimmune encephalomyelitis (EAE) as well as in severe forms of allergic asthma $[21,22]$. Indeed, in a number of autoimmune disease models the presence of SFB as part of the microbiota resulted in more severe pathology [23, $24,25]$. Whether Th17 cells differentiated in the intestine do also contribute to asthma exacerbation in the lung is not known. However, a recent report shows that Th17 cells from SFB-positive mice contain a T cell receptor repertoire that is essentially specific to SFB-derived peptides [26]. This finding does not support the possibility that Th17 cells primed in the gut in response to SFB colonization exacerbate immune reactions to allergens elsewhere.

\section{Microbiota and type $\mathbf{2}$ immune responses}

How does the microbiota impact on allergic disorders and notably on the generation of Th2 cells?

Currently, there is no evidence for a direct influence of the microbiota on the differentiation of Th2 cells. However, a number of studies addressed this issue indirectly by analyzing Th2-dominated immune responses in mice that had been treated with broad-spectrum antibiotics or raised under germfree conditions. First, in the lung, the complete absence of microbes leads to a more severe form of ovalbumin-induced allergic airway inflammation [27]. Similarly, the treatment with antibiotics early in life resulted in a profound increase of susceptibility to allergic airway inflammation [28]. Of note, the frequency of Tregs, whereas reduced in the gut, was not affected in the lung [28]. Furthermore, in a model for allergic airway inflammation to house dust mite (HDM) more severe allergic immune reactions were observed in the lung of very young mice compared to older mice and this effect correlated with incomplete microbial colonization of the lung at this age [29]. In this study, an altered phenotype of antigen-presenting cells and reduced frequencies of Tregs have been observed in the lung which may link the developing microbiota to the in duction of Tregs and the perinatal acquirement of tolerance in the lung [29].

Besides the microbiota, reduced infection rates with helminth parasites in westernized countries have been proposed to contribute to higher frequencies of immune-mediated diseases [30]. Helminth parasites can induce de novo Treg differentiation [31] but also shape the microbiota in a way to induce higher production of SCFA and thus Treg induction $[14,15]$ which results in protection from allergic airway inflammation $[32,33]$. In an attempt to analyze the impact of the human microbiota on allergic susceptibility, Finlay and colleagues recently identified a cluster of individual bacterial strains in the feces of human newborns prior to disease onset that negatively correlated with the later development of atopy and wheeze - both hallmarks of high asthma risk [34]. Re-colonization of germfree mice with human microbiota supplemented with these bacteria resulted in lower allergic airway inflammation pathology in the following generation indicating a protective effect of these bacterial strains [34].

Not only the microbiota does impact immunity during an ongoing immune response, it also shapes the immune status at steady state. To that effect, IgE levels in germfree mice are in general severely increased, which is in sharp contrast to all other immunoglobulin subtypes [35]. Neonatal recolonization of these mice with a standard flora reversed this increase of IgE [35]. In terms of IgE-dependent effector cells, the microbiota also limits basophil differentiation from hematopoietic precursors in the bone marrow as systemic basophil numbers are enhanced in germfree as compared to microbiota-sufficient mice [36].

The highest microbial exposure to the host takes place at the gut epithelium and thus, its effects on type 2 immune responses can be expected to be strongest at this site. In a murine model of orally in- 
duced food allergy antibiotic-treated as well as germfree mice showed more efficient sensitization to peanut extract that resulted in more severe anaphylactic reactions upon systemic allergen challenge [37]. Besides its role for the development of the immune system, the microbiota also affects the mucus layer and regulates the permeability of the epithelial barrier. Indeed, more peanut allergens were found in the serum of sensitized germfree mice compared to conventionally housed mice [37]. Besides allergic inflammation, ulcerative colitis is another non-infectious disease which is (at least in part) based on a type 2 immunopathology [38]. Again, the induction of an ulcerative colitis-like disease in mice leads to an exaggerated immunopathology in mice raised under germfree conditions compared to conventionally housed mice [39]. Certain NKT cell subsets within mucosal surfaces may at least in part account for this effect, even though additional players may be involved [39]. Finally, colonization of mice with murine or human symbiotic Clostridia consortia - which boost Treg numbers in the intestinal tract - led to reduced secretion of IL-4 from restimulated splenocytes and ameliorated the pathology in an allergic diarrhea model $[9,40]$.

These observations from murine studies can be seen in light of the observation that T cells isolated from the cord blood of (almost sterile) newborns show a bias towards the secretion of type 2 cytokines [41]. It has therefore been proposed that humans are born with a "type 2 immune bias", the reason of which remains to be established [42]. This bias is thought to be counteracted through the in duction of Th1, Th17 or Tregs after colonization with a symbiotic microbiota. Altogether, there is accumulating evidence that colonization with a complex microbiota plays a key role in dampening type 2 immune responses at various mucosal sites.

\section{Regulatory T cells and control of type 2 immune responses}

Tregs are known key players in the regulation of adaptive immune responses. The identification of the transcription factor Foxp3 was the starting point to a precise identification of these immune regulatory Tcells and allowed to study their function in a variety of diseases: the ablation of the Foxp3 gene in mice leads to an autoimmune disorder known as the "scurfy" phenotype characterized by hyper-activation of T cells, production of auto-antibodies, wasting disease, and early death [43]. Similarly, dysfunction of Foxp3 and thus Treg function in humans is known as the IPEX syndrome (immunodysregulation polyendocrinopathy $\mathrm{X}$-linked syndrome), a rare genetic disease that results in autoimmune enteropathy, different forms of dermatitis, and autoimmune endocrinopathy $[44,45]$.
Developing thymocytes are negatively selected in the thymus by their reactivity against self-MHC-II complexes: whereas strong affinities are deleted (negative selection), intermediate responses can induce Treg differentiation [46]. Therefore, it is believed that such thymic Tregs (tTregs) preferentially recognize self-antigens and are crucial to actively prevent autoimmunity [47]. In contrast, the majority of Tregs isolated from the colon have a T cell receptor (TCR) specificity that recognizes microbiota-derived antigens and may therefore not be thymus-derived [48] even though some thymic Tregs may contribute to microbiota recognition [49]. Naive Tcells in the periphery naturally encounter tissue-restricted self-antigens that are not expressed in the thymus. This can lead to their differentiation into Tregs in the periphery [50]. Interestingly, these peripherally-induced Tregs - that are specific for self-antigens - do express Helios (encoded by Ikzf2) [50], a transcription factor that has been proposed to be mainly expressed by thymic-derived Tregs [51]. Naive Tcells can also encounter a variety of non-self antigens including potential allergens in the periphery. The highest probabilities for such contacts are at mucosal surfaces and associated lymphoid tissues especially within the intestinal tract. At this site, both foodand bacterial-derived antigens (or even viral or fungal antigens) create an enormous reservoir for potential antigens during the lifetime of an individual. It can be expected that naive T cells encountering such antigens become anergic or even get deleted and only few T cells will differentiate to Tregs because there is only a restricted "niche" for Tregs at each anatomical site (Fig. 1).

Is there a general link of Tregs to allergic disorders? There is accumulating evidence that the presence and function of Foxp $3^{+}$Tregs is directly linked to IgE levels and thus to susceptibility to allergic disorders.

Firstly, for both mice and humans it was shown that a constitutive deficiency in the expression of Foxp3 - and therefore also in functional Tregs results spontaneously in very high levels of serum $\operatorname{IgE}[44,52]$. The absence of functional antigen-specific Tregs has also been associated with a dysregulated Th2 response in ovalbumin-induced allergic airway inflammation even though other features of lung inflammation remained unaltered [53].

Secondly, the specific knockout of several pathways or costimulatory molecules within Foxp $3^{+}$Tregs in mice has been associated with spontaneously increased IgE levels: the knockout of interferon regulatory factor 4 (IRF4) in Tregs results in enhanced generation of Th2 cells and plasma cells that generate high levels of IgE [54]. 


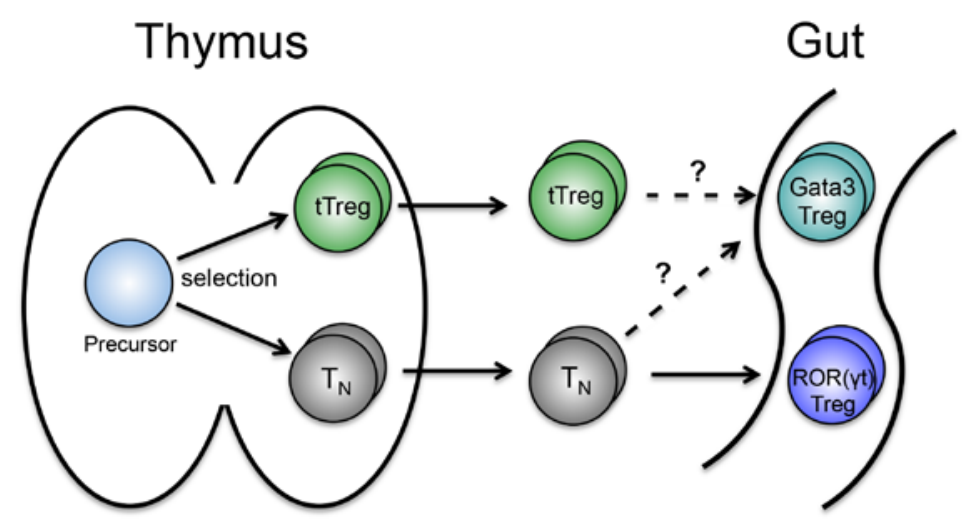

tTreg, Thymic Treg; ROR(yt), Retinoic acid-related orphan receptor gamma t; TN, naïve T cells

Fig. 1: Source of intestinal regulatory T cell subsets. Positive and negative selection in the thymus leads to an output of naïve Thelper cells and Tregs. Naive T cells can still differentiate into Tregs in the gut or associated lymphoid tissues and mostly co-express ROR( $\gamma t)$. Gata3+ Tregs can develop in the absence of a symbiotic microbiota and may therefore be rather of thymic origin at steady state conditions. Gata3+ Tregs may still differentiate from naïve $T$ cells under inflammatory conditions or conditions leading to a failure in the differentiation of $\mathrm{ROR}(\gamma \mathrm{t})+$ Tregs. Thus, both thymic and peripherally induced Tregs may contribute to the total Treg pool in the gut to maintain intestinal immune homeostasis.

Similarly, the knockout of the cytotoxic T lymphocyte antigen 4 (CLTA-4) in Tregs results in fatal autoimmunity characterized among other defects by heightened IgE levels and increased numbers of IL-4 producing Th2 cells [55].

Thirdly, the specific knockout of a conserved non-coding DNA sequence element next to the Foxp3 promoter called CNS1 leads to a complete failure in the generation of induced Tregs. This deficiency results in an age-dependent mucosal inflammation characterized by higher frequencies of Th2 cells in the intestinal lamina propria and increased IgE and IgA levels [56].

Fourthly, a recent human study with children of high risk for peanut allergy revealed a clear protective effect for an early in life contact to peanuts: when children ate a predefined weekly amount of peanuts in the first five years, the children were protected from the later development of peanut-specific allergy [57]. This study changed the previous recommendation for allergic parents to avoid early contact of their children with potential allergens whenever possible. In contrast, this study indicates an active induction of peripheral tolerance in the gut and one can speculate that induction of antigen-specific Tregs may be one reason for this active tolerance induction. In fact, all kinds of potential immunologically not-ignored allergens may induce Tregs in the periphery in healthy individuals that will suppress the potential differentiation of allergen-specific $\mathrm{Th} 2$ responses and IgE antibodies. It is possible that this Treg induction is more likely to occur early in life than in adulthood for reasons that remain to be determined.

\section{Novel intestinal Treg subpopulations}

The differentiation of Thelper cells is regulated through cytokine signals that result in the expression of key lineage-determing transcription factors. Surprisingly, Tregs can also co-express some of these transcription factors [58]. Others and we recently found that non-self specific Tregs in the gut do not express Helios but surprisingly express the pro-inflammatory transcription factor retinoic acid-related orphan receptor gammat $[\operatorname{ROR}(\gamma \mathrm{t})]^{\star}[59$, 60]. $\operatorname{ROR}(\gamma t)$ has been identified as key transcription factor of so-called innate lymphoid cells type 3 (ILC3) including lymphoid tissue inducer cells [61]. Therefore, $\operatorname{ROR}(\gamma \mathrm{t})$-deficient mice are completely devoid of secondary lymphoid organs [62]. Subsequently, $\operatorname{ROR}(\gamma \mathrm{t})$ was found to be a necessary transcription factor for the differentiation of Th17 cells [63]. We found that $\operatorname{ROR}(\gamma t)$-deficient mice show an increased pathology after induction of a dextran sulfate sodium (DSS)-mediated colitis possibly through the generation of supernumerary numbers of tertiary lymphoid tissues in the colon and thus bacteria-specific, pathological IgG antibodies [64]. However, Tregs expressing ROR $(\gamma \mathrm{t})$ can be found in the gut at high frequencies and may also contribute to dampen inflammatory diseases in the gut $[65,66]$. Indeed, $\operatorname{ROR}(\gamma t)^{+}$Tregs were at least as efficient as their $\operatorname{ROR}(\gamma \mathrm{t})^{-}$Treg counterparts in in vitro suppression assays and are therefore true regulatory Tcells [65]. For a long time, ROR $(\gamma t) /$ Foxp3-co-expressing cells have been seen as intermediates between Th17 and Tregs that are not yet fully committed to one or the other lineage [66].

Others and we have now shown that these $\operatorname{ROR}(\gamma t)^{+}$Tregs represent a stable population of Tregs that exert a critical regulatory function in the gut $[59,60,67]$ : firstly, the highest frequency of $\operatorname{ROR}(\gamma \mathrm{t})^{+}$Tregs can be found in the intestinal lamina propria of mice after weaning and their frequency seems to correlate with the bacterial load (and thus possibly with antigen exposure) because their frequency increases from esophagus to small intestine to colon.

Phenotypically, these cells have a very active phenotype including low expression of CD62L, high expression of $\mathrm{CD} 44$, high levels of the regulatory molecules CTLA-4, ICOS, CD39, and CD73. They

*The human counterpart of ROR( $\gamma \mathrm{t})$ is RORC2. To improve readability, only the abbreviation "ROR( $\gamma t)$ " is used throughout this article. 
do not express Helios and only low levels of Neuropilin-1. This phenotype is in accordance with an induced nature of Tregs in response to foreign non-self antigens. Importantly, the analysis of $\operatorname{ROR}(\gamma \mathrm{t})$-deficient mice revealed that the Treg compartment in the intestinal lamina propria is completely devoid of Helios- Tregs [60] and thus iTregs with a specificity for non-self antigens [60]. Additionally, the transfer of naive $\mathrm{T}$ cells followed by the oral application of the antigen leads to a preferential induction of $\operatorname{ROR}(\gamma t)^{+}$Tregs in the intestinal lamina propria (Fig. 1). In line with this observation, the constitutive ablation of dendritic cells or MHC-II molecules prevents the induction of normal amounts of $\operatorname{ROR}(\gamma t)^{+}$Tregs but not $\operatorname{ROR}(\gamma t)^{-}$Tregs [60]. Constitutive ablation of dendritic cells has been previously associated with failed central tolerance induction and thus autoimmunity but not with failed Treg induction [68]. Importantly, $\operatorname{ROR}(\gamma \mathrm{t})^{+}-$ Tregs show a stable phenotype in vitro and in vivo and also have a fully demethylated TSDR (Treg-specific demethylated region) of the Foxp3 promoter and other key regulatory molecules [67]. Therefore, one can expect that $\operatorname{ROR}(\gamma \mathrm{t})^{+}$Tregs are rather stable and execute an important regulatory function in the gut at steady state.

To assess the direct impact of the microbiota on $\operatorname{ROR}(\gamma \mathrm{t})^{+}$Tregs, broad-spectrum antibiotic treated mice or mice raised under germfree conditions have been analyzed. Indeed, the frequency of $\operatorname{ROR}(\gamma t)^{+}$ Tregs was drastically reduced in both cases and the transfer of germfree mice to a microbial-containing environment rapidly re-induced normal $\operatorname{ROR}(\gamma \mathrm{t})^{+}$ Treg numbers [60]. The group of Benoist C. analyzed in detail which bacterial strains are the best inducers of $\operatorname{ROR}(\gamma t)^{+}$Tregs and found indeed a selective capacity of individual strains to perform better than others [59]. However, there was no general pattern detectable among the inducers and the non-inducers until now. This finding may indicate that rather than bacterial family relativeness shared metabolic pathways play a dominant role in terms of $\operatorname{ROR}(\gamma t)^{+}$Treg induction. It should be noted that colonization with a clostridia consortium - that has been previously associated to Treg induction - preferentially but not exclusively induces $\operatorname{ROR}(\gamma \mathrm{t})^{+}$ Tregs $[59,60]$. Similarly, we found a biased induction of $\operatorname{ROR}(\gamma \mathrm{t})+$ Tregs after treatment with the SCFA butyrate but Sefik et al. did not. Notably, also SFB were able to induce some $\operatorname{ROR}(\gamma \mathrm{t})^{+}$Tregs albeit to a lower extent than Th17 cells $[59,60]$.

Besides the microbiota, also diet can influence the intestinal immune system. The vitamin A metabolite retinoic acid has been shown to enhance the in duction of Tregs in vitro $[65,69]$. Importantly, the absence of retinoic acid can alter the balance between ILC2 and ILC3 and thereby cause a type 2 immune deviation within the mucosal immune system [70]. We found that both blocking of the receptor for vitamin A with an inhibitor or feeding mice a vitamin A-deficient diet results in reduced frequencies of $\operatorname{ROR}(\gamma t)+$ Tregs [60]. Whether retinoic acid-mediated immune deviation from type 2 to type 3 immunity in both adaptive and innate immunity is functionally linked remains an open question.

Which cell-intrinsic factors do regulate the induction of $\operatorname{ROR}(\gamma \mathrm{t})^{+}$Tregs? The shared expression of $\operatorname{ROR}(\gamma \mathrm{t})$ between Th17 cells and iTregs in the gut indicates a shared transcriptional program for the differentiation of both subtypes. Indeed, the knockout of IL-6 and its signal transducer STAT3 (both of which critical factors for the differentiation of Th17 cells) results in reduced frequencies of $\operatorname{ROR}(\gamma \mathrm{t})+$ Tregs. For the effect of IL-23, a cytokine involved in Th17 cell differentiation, the Benoist group and we obtained divergent results: in the absence of IL-23, we observed a reduced frequency of $\operatorname{ROR}(\gamma \mathrm{t})^{+}$Tregs whereas the group of Benoist did not $[59,60]$. The role of IL-23 for Th17 is still incompletely understood but it seems that IL-23 is only required for stabilization rather than initiation of the Th17 program [21]. The contrasting results of IL-23 for the induction or maintenance of $\operatorname{ROR}(\gamma t)+$ Tregs may therefore reflect the local microbiota composition and its relative stability in different animal facilities.

It should be noted that during the resolution of an inflammation, $\operatorname{ROR}(\gamma \mathrm{t})+$ Th17 can also trans-differentiate into Foxp $3^{-}$regulatory T cells expressing the anti-inflammatory cytokine IL-10 [71]. Only few ROR $(\gamma \mathrm{t})^{+}$Foxp $3^{+}$Tregs are directly generated from exTh17 cells $[67,71]$. This may reflect the circumstance that a massive expansion of Th17 cells during inflammation occurs and only a limited niche for Tregs exists to enable tolerance to symbiotic microbes. Nevertheless, it seems that $\operatorname{ROR}(\gamma t)+$ Tregs co-opt the transcriptional machinery of the Th17 differentiation program and the local micromilieu dictates the outcome between Th17 or $\operatorname{ROR}(\gamma \mathrm{t})^{+}$ Tregs.

Given that $\operatorname{ROR}(\gamma \mathrm{t})^{+}$Tregs are highly abundant in the intestinal lamina propria, the functional role of these cells for the intestinal immune homeostasis remained an open question. To this end, we first analyzed $\operatorname{ROR}(\gamma \mathrm{t})$-deficient mice at steady state and found sometimes drastically enhanced frequencies of Gata $3^{+}$Th 2 cells and increased levels of serum IgE, one of the hallmarks of allergic predisposition [60]. In an attempt to specifically knockout $\operatorname{ROR}(\gamma \mathrm{t})$ in Tregs, the group of Benoist and we crossed mice expressing the Cre recombinase under control of the Foxp3 promoter with mice bearing floxed $\operatorname{ROR}(\gamma \mathrm{t})$ alleles. We found that these Foxp $3^{\mathrm{Cre}} \times \operatorname{ROR}(\gamma \mathrm{t})^{\mathrm{FL} / \mathrm{FL}}$ 
mice showed slightly reduced frequencies of $\mathrm{He}$ lios ${ }^{-}$Foxp $3^{+}$iTregs in the small intestinal lamina propria. In parallel to the genetically induced reduction of $\operatorname{ROR}(\gamma t)^{+}$Tregs, we found a relative increase of Gata3 ${ }^{+}$Tregs and a slight increase of Gata3 ${ }^{+}$ Th2 cells and serum IgE levels. These results indicate that $\operatorname{ROR}(\gamma \mathrm{t})^{+}$Tregs may regulate the induction of intestinal Th2 cells and may therefore enhance the systemic susceptibility to allergic disorders even at steady state.

In order to boost a Th2-driven inflammatory disorder, we treated mice with oxazolone to induce a type 2-dominated inflammation in the colon resembling human ulcerative colitis [38]. The selective knockout of $\operatorname{ROR}(\gamma t)$ in Tregs resulted in a drastically enhanced pathology, enhanced secretion of type 2 cytokines of restimulated T cells, and sometimes death [60]. In contrast, the group of Benoist observed an exaggerated Th1- and Th17-driven immune pathology in a different colitis model using the same conditional knockout mice [59]. The combination of both studies may reflect the influence of the individual microbiome on the type of immune deviation in the absence of $\operatorname{ROR}(\gamma \mathrm{t})^{+}$Treg-mediated immune regulation.

Our results point towards a $\operatorname{ROR}(\gamma t)^{+}$Treg-mediated control of Th2-driven immune responses. In contrast, it is well known that helminth infections are cleared by the immune system through the induction of sometimes very strong type 2 immune responses. We reasoned therefore that in such a scenario the absence of $\operatorname{ROR}(\gamma \mathrm{t})^{+}$Tregs could be beneficial for the host. Indeed, we found a lower egg burden after infection with the helminth parasite Heligmosomoides polygyrus in Foxp $3^{\mathrm{Cre}} \times \mathrm{ROR}(\gamma \mathrm{t})^{\mathrm{FL} / \mathrm{FL}}$ mice that was paralleled by increased secretion of type 2 cytokines [60].

But how can $\operatorname{ROR}(\gamma t)^{+}$Treg exert this specific function? In general, it is not really known by which of their multiple regulatory mechanism Tregs exert their regulatory function in a defined immune response. Nevertheless, we found that $\operatorname{ROR}(\gamma t)^{+}$Tregs may alter the phenotype of intestinal dendritic cells because Foxp $3^{\mathrm{Cre}} \mathrm{x}$ ROR $(\gamma \mathrm{t})^{\mathrm{FL} / \mathrm{FL}}$ mice showed lower levels of the costimulatory receptors CD80 and CD86 [60] similar to what has been observed in CTLA-4-deficient Tregs [55]. ROR $(\gamma t)^{+}$Tregs do express high levels of CTLA-4 and IRF4 at steady state which is in line with the Th2 bias observed in mice with a selective defect of these molecules in Foxp $3^{+}$Tregs $[54,55]$. Altogether, these results point towards a fundamental role of $\operatorname{ROR}(\gamma t)+$ Tregs in the control of Th2-dominated immune responses under certain circumstances (Fig. 2). As the differentiation of Th17 cells and $\operatorname{ROR}(\gamma \mathrm{t})^{+}$Tregs seem to share at least some transcriptional programs, one can ask whether this program is generally used to counteract Th2 immune responses. Indeed, one study recently highlighted a possible Th2 and Th17 counter regulation in the case of allergic asthma [72]. This does not exclude that mixed Th2/Th17 phenotypes of allergic disorders exist because genetic factors may unleash this reciprocal regulation and result in even more severe forms of allergic asthma $[73,74]$.

Besides $\operatorname{ROR}(\gamma t)^{+}$Tregs, another population of Tregs expressing the transcription factor Gata3 has been observed in the intestinal tract $[75,76]$. Both $\operatorname{ROR}(\gamma \mathrm{t})^{+}$and Gata3 ${ }^{+}$Treg subsets are mutually exclusive under healthy conditions $[60,75]$. Powrie and colleagues recently provided evidence that Gata3 expression in Tregs is induced upon stimulation with the epithelial-derived cytokine IL-33 [77]. Furthermore, Gata3 expression in Tregs is necessary for prevention of a spontaneous inflammatory disorder and effective suppression of a transfer colitis [76, 77]. However, $\operatorname{ROR}(\gamma \mathrm{t})^{+}$Tregs have been shown to protect more efficiently than $\operatorname{ROR}(\gamma \mathrm{t})^{-}$ Tregs in this transfer colitis model [67] raising the question of whether both subsets use different mechanisms to suppress Tcell proliferation in a lymphopenic environment. Two observations make it unlikely that Gata3 ${ }^{+}$Tregs are induced upon recognition of foreign antigens/allergens: firstly, Gata $3^{+}$ Tregs do at least to a certain degree express Helios (and may thus be rather of thymic origin and/or recognize self antigens) and secondly, Gata $3^{+}$Tregs can still be found in germfree mice [60] (Fig. 1). In germfree mice, a different cytokine pattern of IL-33 and IL- 6 among others may shape the distribution of Treg subsets in the gut $[60,77]$. In a model of food allergy, Gata3 ${ }^{+}$Tregs emerge as a consequence of enhanced IL-4 receptor signaling making such Gata3 $^{+}$Tregs less efficient in protection from and possibly even a driver of food allergy due to high IL-4 expression [78]. Conversely, Gata3-deficient Tregs have a higher chance to adopt a Th17-like cytokine expression profile [76]. These observations may have important consequences for immunotherapy of allergic patients because the presence of Th2like Tregs may prevent therapy or even aggravate immune pathology in established food allergy and possibly explains limited success of oral immunotherapy so far [79].

\section{Conclusion}

The hygiene hypothesis postulates a change of life style factors in westernized countries as one reason for an increase of allergic disorders. Of note, most of these life style factors can influence directly or indirectly the composition of our microbiota. This "altered" microbiota may - for reasons that remain to be discovered - favor the differentiation of intestinal Th2 cells in the absence of Treg-mediated im- 


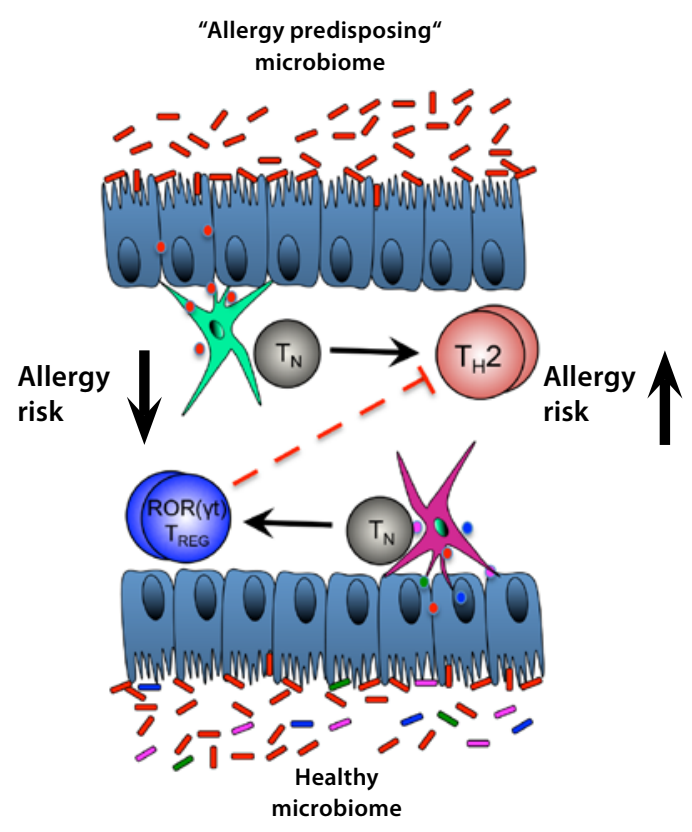

Treg, regulatory $T$ cells; $R O R(\gamma t)$, Retinoic acid-related orphan receptor gammat; $T N$, naïve Tcells, Th, Thelpercell

Fig. 2: Suppression of type 2 immune responses through type 3 regulatory T cells. Possible mechanism for the relation between microbiota, $\mathrm{ROR}(\gamma \mathrm{t})^{+}$Tregs, and prevention of pro-allergic Th2 immune responses. Unwanted Th2 differentiation in response to harmless foreign antigens such as allergens is suppressed through the induction of $\mathrm{ROR}(\gamma \mathrm{t})^{+}$Tregs under healthy conditions. Th2 differentiation may be favored through an "altered" microbiota at mucosal sites.

mune regulation (Fig. 2). Inefficient mucosal Treg induction or maintenance may be the result of a genetic predisposition or itself the result of an altered microbiota. According to this hypothesis, a combination of both factors results in an enhanced susceptibility to allergic disorders or other inflammatory diseases.

Several questions remain open: is Treg-mediated control antigen-specific or rather the result of a general setting of the immune status? If the gut-derived immune regulation is antigen-specific, are allergic disorders the result of cross-reactivity with microbiota-derived antigens? Or are most allergens normally present in the intestinal tract and induce antigen-specific tolerance at steady state conditions? Therefore, it remains to be determined whether the nature and specificities of intestinal Treg subpopulations can explain the observed increases in allergic disorders in westernized countries. Most of the studies including our own do not directly address the role of Tregs for allergic onset or allergic suscep- tibility. It will be important to analyze how the absence or an imbalance between Treg subpopulation reflect an alteration of allergic susceptibilities and whether this knowledge can be used to design novel prevention strategies.

\author{
Dr. Caspar Ohnmacht \\ Institute for Allergy Research \\ Center of Allergy \& Environment (ZAUM) \\ Technische Universität München \& \\ Helmholtz Zentrum München \\ Ingolstädter Landstraße 1 \\ 85764 Neuherberg \\ Germany \\ E-Mail: caspar.ohnmacht@helmholtz-muenchen.de
}

\section{Acknowledgement}

The author thanks C. Schmidt-Weber and S. Haak for critical review of the manuscript.

\section{Conflict of interest}

The author declares that there are no conflicts of interest.

Cite this as

Ohnmacht C. Microbiota, regulatory T cell subsets, and allergic disorders. Allergo J Int 2016;25:114-23

DOI: 10.1007/s40629-016-0118-0

\section{References}

1. Le Gros G, Ben-Sasson SZ, Seder R, Finkelman FD, Paul WE. Generation of interleukin 4 (IL-4)-producing cells in vivo and in vitro: IL-2 and IL-4 are required for in vitro generation of IL-4-producing cells. J Exp Med 1990;172:921-9

2. Mohrs M, Shinkai K, Mohrs K, Locksley RM. Analysis of type 2 immunity in vivo with a bicistronic IL-4 reporter. Immunity 2001;15:303-11

3. Neill DR, Wong SH, Bellosi A, Flynn RJ, Daly M, Langford TK et al. Nuocytes represent a new innate effector leukocyte that mediates type-2 immunity. Nature 2010;464:1367-70

4. Mosmann TR, Coffman RL. TH1 and TH2 cells: different patterns of lymphokine secretion lead to different functional properties. Annu Rev Immunol 1989;7:145-73

5. Strachan DP. Hay fever, hygiene, and household size. BMJ 1989;299:1259-60

6. Ege MJ, Mayer M, Normand AC, Genuneit J, Cookson WO, Braun-Fahrlander $\mathrm{C}$ et al. Exposure to environmental microorganisms and childhood asthma.

N Engl J Med 2011;364:701-9

7. von Mutius E, Weiland SK, Fritzsch C, Duhme H, Keil U. Increasing prevalence of hay fever and atopy among children in Leipzig, East Germany. Lancet 1998;351:862-6

8. Schuijs MJ, Willart MA, Vergote K, Gras D, Deswarte K, Ege $M J$ et al. Farm dust and endotoxin protect against allergy through A20 induction in lung epithelial cells. Science 2015;349:1106-10

9. Atarashi K, Tanoue T, Shima T, Imaoka A, Kuwahara T, Momose $Y$ et al. Induction of colonic regulatory $T$ cells by indigenous Clostridium species. Science 2011;331:337-41

10. Geuking MB, Cahenzli J, Lawson MA, Ng DC, Slack E, Hapfelmeier $S$ et al. Intestinal bacterial colonization induces mutualistic regulatory $T$ cell responses. Immunity 2011;34:794-806

11. Naik S, Bouladoux N, Wilhelm C, Molloy MJ, Salcedo R, Kas tenmuller W et al. Compartmentalized control of skin immunity by resident commensals. Science 2012;337:1115-9 
12. Mazmanian SK, Liu CH, Tzianabos AO, Kasper DL. An immunomodulatory molecule of symbiotic bacteria directs maturation of the host immune system. Cell 2005;122: 107-18

13. Round JL, Mazmanian SK. Inducible Foxp3+ regulatory T-cell development by a commensal bacterium of the intestinal microbiota. Proc Natl Acad Sci U S A 2010;107: 12204-9

14. Arpaia N, Campbell C, Fan X, Dikiy S, van der Veeken J, deRoos $\mathrm{P}$ et al. Metabolites produced by commensal bacteria promote peripheral regulatory $\mathrm{T}$-cell generation. Nature 2013;504:451-5

15. Furusawa Y, Obata Y, Fukuda S, Endo TA, Nakato G, Takahashi $D$ et al. Commensal microbe-derived butyrate induces the differentiation of colonic regulatory T cells. Nature 2013;504:446-50

16. Tao R, de Zoeten EF, Ozkaynak E, Chen C, Wang L, Porrett $P M$ et al. Deacetylase inhibition promotes the generation and function of regulatory T cells. Nat Med 2007;13: 1299-307

17. Chapman MA, Grahn MF, Giamundo P, O'Connell PR, Onwu D, Hutton $M$ et al. New technique to measure mucosal metabolism and its use to map substrate utilization in the healthy human large bowel. Br J Surg 1993;80: $445-9$

18. Ivanov, II, Atarashi K, Manel N, Brodie EL, Shima T, Karaoz U et al. Induction of intestinal Th17 cells by segmented filamentous bacteria. Cell 2009;139:485-98

19. Ohnmacht $C$, Marques R, Presley L, Sawa S, Lochner M, Eberl G. Intestinal microbiota, evolution of the immune system and the bad reputation of pro-inflammatory immunity. Cell Microbiol 2011;13:653-9

20. Ishigame H, Kakuta $S$, Nagai T, Kadoki M, Nambu A, Komiyama $\mathrm{Y}$ et al. Differential roles of interleukin-17A and -17F in host defense against mucoepithelial bacterial infection and allergic responses. Immunity 2009;30:108-19

21. Korn T, Bettelli E, Oukka M, Kuchroo VK. IL-17 and Th17 Cells. Annu Rev Immunol 2009;27:485-517

22. Kudo M, Melton AC, Chen C, Engler MB, Huang KE, Ren X et al. IL-17A produced by alphabeta T cells drives airway hyper-responsiveness in mice and enhances mouse and human airway smooth muscle contraction. Nat Med 2012;18:547-54

23. Kriegel MA, Sefik E, Hill JA, Wu HJ, Benoist C, Mathis D. Naturally transmitted segmented filamentous bacteria segregate with diabetes protection in nonobese diabetic mice. Proc Natl Acad Sci U S A 2011;108:11548-53

24. Wu HJ, Ivanov, II, Darce J, Hattori K, Shima T, Umesaki Y et al. Gut-residing segmented filamentous bacteria drive autoimmune arthritis via T helper 17 cells. Immunity 2010; 32:815-27

25. Lee YK, Menezes JS, Umesaki Y, Mazmanian SK. Proinflammatory $\mathrm{T}$-cell responses to gut microbiota promote experimental autoimmune encephalomyelitis. Proc Natl Acad Sci U S A 2011;108 Suppl 1:4615-22

26. Yang $Y$, Torchinsky MB, Gobert $M$, Xiong $H$, Xu M, Linehan $J$ et al. Focused specificity of intestinal TH17 cells towards commensal bacterial antigens. Nature 2014;510:152-6

27. Herbst T, Sichelstiel A, Schar C, Yadava K, Burki K, Cahenzli $J$ et al. Dysregulation of allergic airway inflammation in the absence of microbial colonization. Am J Respir Crit Care Med 2011;184:198-205

28. Russell SL, Gold MJ, Hartmann M, Willing BP, Thorson L, Wlodarska $M$ et al. Early life antibiotic-driven changes in microbiota enhance susceptibility to allergic asthma. EMBO Rep 2012;13:440-7

29. Gollwitzer ES, Saglani S, Trompette A, Yadava K, Sherburn $\mathrm{R}, \mathrm{McC}$ oy KD et al. Lung microbiota promotes tolerance to allergens in neonates via PD-L1. Nat Med 2014; 20:642-7

30. Maizels RM, Yazdanbakhsh M. Immune regulation by helminth parasites: cellular and molecular mechanisms. Nat Rev Immunol 2003;3:733-44
31. Wilson MS, Taylor MD, Balic A, Finney CA, Lamb JR, Maizels $\mathrm{RM}$. Suppression of allergic airway inflammation by helminth-induced regulatory T cells. J Exp Med 2005;202: 1199-212

32. Zaiss MM, Rapin A, Lebon L, Dubey LK, Mosconi I, Sarter K et al. The Intestinal Microbiota Contributes to the Ability of Helminths to Modulate Allergic Inflammation. Immunity 2015;43:998-1010

33. Trompette A, Gollwitzer ES, Yadava K, Sichelstiel AK, Sprenger N, Ngom-Bru C et al. Gut microbiota metabolism of dietary fiber influences allergic airway disease and hematopoiesis. Nat Med 2014;20:159-66

34. Arrieta MC, Stiemsma LT, Dimitriu PA, Thorson L, Russell S, Yurist-Doutsch $S$ et al. Early infancy microbial and metabolic alterations affect risk of childhood asthma. Sci Transl Med 2015;7:307ra152

35. Cahenzli J, Koller Y, Wyss M, Geuking MB, McCoy KD. Intestinal microbial diversity during early-life colonization shapes long-term IgE levels. Cell Host Microbe 2013;14: 559-70

36. Hill DA, Siracusa MC, Abt MC, Kim BS, Kobuley D, Kubo M et al. Commensal bacteria-derived signals regulate basophil hematopoiesis and allergic inflammation. Nat Med 2012;18:538-46

37. Stefka AT, Feehley T, Tripathi P, Qiu J, McCoy K, Mazmanian SK et al. Commensal bacteria protect against food allergen sensitization. Proc Natl Acad Sci U S A 2014;

38. Boirivant M, Fuss IJ, Chu A, Strober W. Oxazolone colitis: A murine model of T helper cell type 2 colitis treatable with antibodies to interleukin 4. J Exp Med 1998;188:1929-39

39. Olszak T, An D, Zeissig S, Vera MP, Richter J, Franke A et al. Microbial exposure during early life has persistent effects on natural killer T cell function. Science 2012;336:489-93

40. Atarashi K, Tanoue T, Oshima K, Suda W, Nagano Y, Nishikawa $\mathrm{H}$ et al. Treg induction by a rationally selected mixture of Clostridia strains from the human microbiota. Nature 2013;500:232-6

41. Prescott SL, Macaubas C, Smallacombe T, Holt BJ, Sly PD, Holt PG. Development of allergen-specific T-cell memory in atopic and normal children. Lancet 1999;353:196-200

42. Li L, Lee HH, Bell JJ, Gregg RK, Ellis JS, Gessner A et al. IL-4 utilizes an alternative receptor to drive apoptosis of Th1 cells and skews neonatal immunity toward Th2. Immunity 2004;20:429-40

43. Fontenot JD, Gavin MA, Rudensky AY. Foxp3 programs the development and function of CD4+CD25+ regulatory $T$ cells. Nat Immunol 2003;4:330-6

44. Wildin RS, Smyk-Pearson S, Filipovich AH. Clinical and molecular features of the immunodysregulation, polyendocrinopathy, enteropathy, X linked (IPEX) syndrome. J Med Genet 2002;39:537-45

45. Roncador G, Brown PJ, Maestre L, Hue S, Martinez-Torrecuadrada JL, Ling KL et al. Analysis of FOXP3 protein expression in human $C D 4+C D 25+$ regulatory $T$ cells at the single-cell level. Eur J Immunol 2005;35:1681-91

46. Hsieh CS, Lee HM, Lio CW. Selection of regulatory T cells in the thymus. Nat Rev Immunol 2012;12:157-67

47. Jordan MS, Boesteanu A, Reed AJ, Petrone AL, Holenbeck $A E$, Lerman MA et al. Thymic selection of CD4+CD25+ regulatory $T$ cells induced by an agonist self-peptide. Nat Immunol 2001;2:301-6

48. Lathrop SK, Bloom SM, Rao SM, Nutsch K, Lio CW, Santacruz $\mathrm{N}$ et al. Peripheral education of the immune system by colonic commensal microbiota. Nature 2011;478:250-4

49. Cebula A, Seweryn M, Rempala GA, Pabla SS, Mclndoe RA, Denning TL et al. Thymus-derived regulatory $T$ cells contribute to tolerance to commensal microbiota. Nature 2013;497:258-62

50. Legoux FP, Lim JB, Cauley AW, Dikiy S, Ertelt J, Mariani TJ et al. CD4(+) T Cell Tolerance to Tissue-Restricted Self Antigens Is Mediated by Antigen-Specific Regulatory T Cells Rather Than Deletion. Immunity 2015;43:896-908 
51. Thornton AM, Korty PE, Tran DQ, Wohlfert EA, Murray PE, Belkaid $Y$ et al. Expression of Helios, an Ikaros transcription factor family member, differentiates thymic-derived from peripherally induced Foxp3+ T regulatory cells. J Immunol 2010;184:3433-41

52. Lin W, Truong N, Grossman WJ, Haribhai D, Williams CB, Wang $J$ et al. Allergic dysregulation and hyperimmunoglobulinemia E in Foxp3 mutant mice. J Allergy Clin Immunol 2005;116:1106-15

53. Curotto de Lafaille MA, Kutchukhidze N, Shen S, Ding Y, Yee $\mathrm{H}$, Lafaille JJ. Adaptive Foxp3+ regulatory T cell-dependent and -independent control of allergic inflammation. Immunity 2008;29:114-26

54. Zheng Y, Chaudhry A, Kas A, deRoos P, Kim JM, Chu TT et al. Regulatory T-cell suppressor program co-opts transcription factor IRF4 to control T(H)2 responses. Nature 2009; 458:351-6

55. Wing $K$, Onishi $Y$, Prieto-Martin $P$, Yamaguchi T, Miyara $M$, Fehervari $Z$ et al. CTLA-4 control over Foxp3+ regulatory $T$ cell function. Science 2008;322:271-5

56. Josefowicz SZ, Niec RE, Kim HY, Treuting P, Chinen T, Zheng $Y$ et al. Extrathymically generated regulatory $T$ cells control mucosal TH2 inflammation. Nature 2012;482:395-9

57. Du Toit G, Roberts G, Sayre PH, Bahnson HT, Radulovic S, Santos AF et al. Randomized trial of peanut consumption in infants at risk for peanut allergy. $N$ Engl J Med 2015:372:803-13

58. Josefowicz SZ, Lu LF, Rudensky AY. Regulatory T cells: mechanisms of differentiation and function. Annu Rev Immunol 2012;30:531-64

59. Sefik E, Geva-Zatorsky N, Oh S, Konnikova L, Zemmour D, McGuire AM et al. MUCOSAL IMMUNOLOGY. Individual intestinal symbionts induce a distinct population of RORgamma(+) regulatory T cells. Science 2015;349:993-7

60. Ohnmacht C, Park JH, Cording S, Wing JB, Atarashi K, Obata $Y$ et al. MUCOSAL IMMUNOLOGY. The microbiota regulates type 2 immunity through RORgammat(+) T cells. Science 2015;349:989-93

61. Sawa S, Cherrier M, Lochner M, Satoh-Takayama N, Fehling $\mathrm{HJ}$, Langa $\mathrm{F}$ et al. Lineage relationship analysis of RORgammat+ innate lymphoid cells. Science 2010;330:665-9

62. Eberl G, Marmon S, Sunshine MJ, Rennert PD, Choi Y, Littman DR. An essential function for the nuclear receptor RORgamma(t) in the generation of fetal lymphoid tissue inducer cells. Nat Immunol 2004:5:64-73

63. Ivanov, II, McKenzie BS, Zhou L, Tadokoro CE, Lepelley A, Lafaille JJ et al. The orphan nuclear receptor RORgammat directs the differentiation program of proinflammatory IL17+ Thelper cells. Cell 2006;126:1121-33

64. Lochner M, Ohnmacht C, Presley L, Bruhns P, Si-Tahar M, Sawa $S$ et al. Microbiota-induced tertiary lymphoid tissues aggravate inflammatory disease in the absence of RORgamma $t$ and LTi cells. J Exp Med 2011;208:125-34

65. Lochner M, Peduto L, Cherrier M, Sawa S, Langa F, Varona $R$ et al. In vivo equilibrium of proinflammatory IL-17+ and regulatory IL-10+ Foxp3+ RORgamma $\mathrm{t}+\mathrm{T}$ cells. J Exp Med 2008;205:1381-93
66. Zhou L, Lopes JE, Chong MM, Ivanov, II, Min R, Victora GD et al. TGF-beta-induced Foxp3 inhibits T(H)17 cell differentiation by antagonizing RORgammat function. Nature 2008;453:236-40

67. Yang BH, Hagemann S, Mamareli P, Lauer U, Hoffmann U, Beckstette $\mathrm{M}$ et al. Foxp3 T cells expressing RORgammat represent a stable regulatory $\mathrm{T}$-cell effector lineage with enhanced suppressive capacity during intestinal inflammation. Mucosal Immunol 2015;

68. Ohnmacht C, Pullner A, King SB, Drexler I, Meier S, Brocker $T$ et al. Constitutive ablation of dendritic cells breaks self-tolerance of CD4 T cells and results in spontaneous fatal autoimmunity. J Exp Med 2009;206:549-59

69. Mucida D, Park Y, Kim G, Turovskaya O, Scott I, Kronenberg $M$ et al. Reciprocal TH17 and regulatory T cell differentiation mediated by retinoic acid. Science 2007;317:256-60

70. Spencer SP, Wilhelm C, Yang Q, Hall JA, Bouladoux N, Boyd A et al. Adaptation of innate lymphoid cells to a micronutrient deficiency promotes type 2 barrier immunity. Science 2014;343:432-7

71. Gagliani N, Vesely MC, Iseppon A, Brockmann L, Xu H, Palm NW et al. Th17 cells transdifferentiate into regulatory T cells during resolution of inflammation. Nature 2015; 523:221-5

72. Choy DF, Hart KM, Borthwick LA, Shikotra A, Nagarkar DR, Siddiqui $S$ et al. TH2 and TH17 inflammatory pathways are reciprocally regulated in asthma. Sci TransI Med 2015;7: 301 ra129

73. Irvin C, Zafar I, Good J, Rollins D, Christianson C, Gorska MM et al. Increased frequency of dual-positive TH2/TH17 cells in bronchoalveolar lavage fluid characterizes a population of patients with severe asthma. J Allergy Clin Immunol 2014:134:1175-86 e7

74. Wang YH, Voo KS, Liu B, Chen CY, Uygungil B, Spoede W et al. A novel subset of $C D 4(+) T(H) 2$ memory/effector cells that produce inflammatory IL-17 cytokine and promote the exacerbation of chronic allergic asthma. J Exp Med 2010;207:2479-91

75. Wohlfert EA, Grainger JR, Bouladoux N, Konkel JE, Oldenhove $\mathrm{G}$, Ribeiro $\mathrm{CH}$ et al. GATA3 controls Foxp3(+) regulatory $T$ cell fate during inflammation in mice. J Clin Invest 2011;121:4503-15

76. Wang Y, Su MA, Wan YY. An essential role of the transcription factor GATA-3 for the function of regulatory T cells. Immunity 2011;35:337-48

77. Schiering C, Krausgruber T, Chomka A, Frohlich A, Adelmann K, Wohlfert EA et al. The alarmin IL-33 promotes regulatory T-cell function in the intestine. Nature 2014;513: 564-8

78. Noval Rivas M, Burton OT, Wise P, Charbonnier LM, Georgiev $\mathrm{P}$, Oettgen $\mathrm{HC}$ et al. Regulatory $\mathrm{T}$ cell reprogramming toward a Th2-cell-like lineage impairs oral tolerance and promotes food allergy. Immunity 2015;42:512-23

79. Jones SM, Burks AW, Dupont C. State of the art on food allergen immunotherapy: oral, sublingual, and epicutaneous. J Allergy Clin Immunol 2014;133:318-23 